\title{
Ocorrência de lagartas em função do manejo de inseticidas e utilização de cultivares de algodoeiro
}

\author{
Amanda Casagrande Pereira ${ }^{1}$, Gustavo Luís Mamoré Martins ${ }^{1}$, Germison Vital Tomquelski \\ ${ }^{1}$ Universidade Estadual de Mato Grosso do Sul, Unidade Universitária de Cassilândia, Cassilândia, Mato grosso do Sul, Brasil. E- \\ mail: amanda_tanabi@hotmail.com,gustavomamore@yahoo.com.br. \\ ${ }^{2}$ Fundação de Apoio à Pesquisa Agropecuária de Chapadão, Chapadão do Sul, Mato Grosso do Sul, Brasil. E-mail: \\ germisom@fundacaochapadao.com
}

Recebido: 12/05/2016; Aceito: 24/06/2016.

\section{RESUMO}

O objetivo do trabalho foi avaliar a ocorrência de lagartas em função do manejo de inseticidas e modos de utilização de cultivares de algodoeiro. O delineamento foi em blocos casualisados, em esquema fatorial $2 \times 3$, com seis tratamentos e cinco repetições, totalizando 30 parcelas. Os tratamentos foram: 1) Cultivar Nuopal (com inseticida) (100\% Bt); 2) Cultivar Deltaopal (com inseticida) (100\% não Bt); 3) Cultivar Nuopal centro (80\%) e bordadura Deltaopal (20\%) (com inseticida) $(80 \% \mathrm{Bt}+20 \%$ não Bt); 4) Cultivar Nuopal (sem inseticida) (100\% Bt); 5) Cultivar Deltaopal (sem inseticida) (100\% não Bt) e 6) Cultivar Nuopal centro (80\%) e bordadura deltaopal (sem inseticida) $(80 \% \mathrm{Bt}+20 \%$ não Bt). Realizaram-se amostragens semanais em 10 plantas por parcela de Alabama argillacea, Heliothis virescens e Spodoptera frugiperda. A ocorrência de A. argillacea e H. virescens foi menor nos tratamentos com a cultivar transgênica. Não ocorreram diferenças entre a cultivares quanto à ocorrência de $S$. frugiperda. O manejo das cultivares com inseticida obteve maior eficiência comparada ao tratamento sem inseticida no controle das lagartas.

Palavras-chave: Gossypium hirsutum, Alabama argillacea, Heliothis virescens, Spodoptera frugiperda, transgênicos.

\section{Caterpillars occurrence on function of the insecticides management and cotton cultivars use}

\begin{abstract}
The study objective was to evaluate the occurrence of larvae due to the management of pesticides and methods of use of cotton cultivars. The design was randomized blocks in factorial $2 \times 3$ with six treatments and five replications, totaling 30 experimental plots. The treatments were: 1) Cultivar Nuopal (with insecticide) (100\% Bt); 2) Cultivar Deltaopal (with insecticide) (100\% non-Bt); 3) Cultivar Nuopal in central (80\%) and Deltaopal in surround (20\%) (with insecticide) $(80 \%+20 \%$ non-Bt Bt); 4) Cultivar NuOpal (without insecticide) (100\% Bt); 5) Cultivar Deltaopal (without insecticide) (100\% non-Bt) and 6) Cultivar Nuopal in central (80\%) and Deltaopal in surround (without insecticide) $(80 \%+20 \%$ non-Bt). The samplings were carried out weekly at 10 plants per plot Alabama argillacea, Heliothis virescens and Spodoptera frugiperda. The occurrence of A. argillacea and $H$. virescens was lower with cultivar genetically modified. There were no differences between cultivars for the occurrence of S. frugiperda. The management of cultivars with insecticide obtained higher efficiency compared to treatment without insecticide in control of caterpillars.
\end{abstract}

Key words: Gossypium hirsutum, Alabama argillacea, Heliothis virescens, Spodoptera frugiperda, transgenics. 


\section{Introdução}

O Brasil apresenta cerca de 1.071 hectares de área cultivada de algodão, onde a maior concentração encontra-se na região Centro-Oeste, seguida pela região Nordeste, em que os estados de Mato Grosso e Bahia são responsáveis por cerca de $85 \%$ da área plantada. Com relação à produção, a safra no estado de Mato Grosso atingiu 2.202,4 mil toneladas de algodão em caroço e 870,0 mil de algodão em pluma, em seguida aparece o estado de Goiás, como segundo maior produtor nacional (CONAB, 2015).

$\mathrm{Na}$ região de cerrado, a cotonicultura apresenta um grande complexo de pragas durante seu ciclo que são capazes de causarem prejuízos consideráveis para o agricultor. As lagartas são consideradas pragas importantes, se destacando o curuquerê-do-algodoeiro Alabama argillacea (Huebner) (Lepidoptera: Noctuidae) (TOMQUELSKI et al., 2007), que em condições climáticas favoráveis têm aumentado as populações deste noctuídeo, comprometendo a produção e sendo necessário altos investimentos para seu controle (FERNANDES et al., 2006). Outras duas espécies de lagartas que tem causado danos significativos em lavouras de algodoeiro no Mato Grosso do Sul é a lagarta das maçãs Heliothis virescens (Fabrícius) (Lepidoptera: Noctuidae) e a lagarta militar Spodoptera frugiperda (Smith) (Lepidoptera: Noctuidae) (TOMQUELSKI; MARTINS, 2013).

O controle de pragas é realizado normalmente com inseticidas, os quais nem sempre são eficientes, além de reduzirem a população de inimigos naturais (PAPA, 2006). Com o advento da biotecnologia, foi desenvolvido um novo método de controle de pragas que consiste nas plantas geneticamente modificadas. Deste modo, o uso de plantas geneticamente modificadas contendo genes da bactéria Bacillus thuringiensis Berliner $(B t)$ visam proteção completa da planta ao longo do seu desenvolvimento contra espécies de lepidópteros e coleópteros e tem alcançado grande destaque no cenário agrícola mundial (JAMES, 2009). Esta bactéria produz diferentes proteínas tóxicas, denominadas cristais, altamente específicas para a ordem Lepidóptera, não afetando o homem, os animais e as plantas (PINTO; FIUZA, 2008).

Uma extensa série de genes de $B$. thuringiensis pode ser utilizada na transgenia, incluindo alguns cultivares de algodoeiro, principalmente os que expressam as toxinas Cry1 Ab, Cry2Ab, Cry1F e Cry1Ac, tais como: WideStrike, Bollgard, Ingard, Vip-Cotton, Fibermax B e Stoneville B (TORRES et al., 2009; PERLAK et al., 2001). No Brasil, a partir de 2005, houve a liberação do cultivar transgênico Nuopal (Bollgard I), que expressa a proteína Cry1Ac, para o controle de algumas espécies de lagartas desfolhadoras do algodoeiro. Essa tecnologia visa ampliar o espectro de controle contra diferentes espécies de lepidópteros-praga (TORRES, 2008). A cultivar Nuopal que expressa a proteína Cry1Ac apresenta eficácia no controle do curuquerê-doalgodoeiro (A. argillacea), da lagarta-das-maçãs ( $H$. virescens) e da lagarta-rosada (Pectinophora gossypiella). A cultivar Deltaopal é convencional (não $B t)$.

Uma das estratégias para evitar o desenvolvimento de pragas resistentes em cultivares de algodoeiro transgênico é o uso de áreas de refúgio. Essa tecnologia consiste na utilização de áreas de algodão não- $B t$ (cultivares convencionais) cultivadas na proporção de pelo menos $20 \%$ do total da área plantada com algodão, e na distância máxima de 800 metros da área com algodão $B t$ (transgênico). Geralmente são plantados no centro cultivares transgênicas e nas bordaduras cultivares não transgênicas (JAMES, 2009; TOMQUELSKI; MARTINS, 2013).

Este modo de utilização de cultivares faz parte das áreas de refúgio que permite a multiplicação de insetos suscetíveis, que irão acasalar com eventuais mariposas resistentes da área $B t \mathrm{e}$, consequentemente, os descendentes também serão suscetíveis, reduzindo as chances de aparecimento de populações de lagartas resistentes aos cultivares Bt (FONTES et al., 2006).

No manejo integrado de pragas no sistema de produção do algodoeiro, existem poucas informações disponíveis sobre as possíveis interações entre ocorrência de lagartas e modos de utilização de cultivares convencionais e transgênicas.

Desse modo, o objetivo desse trabalho foi avaliar a ocorrência de lagartas em função do manejo de inseticidas e modos de utilização de cultivares de algodoeiro.

\section{Material e Métodos}

O experimento foi desenvolvido na safra 2006/2007, na área experimental da Fundação de Apoio à Pesquisa Agropecuária de Chapadão, Fundação Chapadão, localizada no município de Chapadão do Sul-MS, a $18^{\circ} 41^{\prime} 33^{\prime \prime} \mathrm{S}$ e $52^{\circ} 40^{\prime} 45^{\prime \prime} \mathrm{W}$ em altitude média de 810 m. O solo da área experimental é classificado como Latossolo Vermelho distroférrico típico muito argiloso (EMBRAPA, 2006), apresentando as seguintes características químicas, na profundidade de $0-20 \mathrm{~cm}$, na instalação do experimento: $\mathrm{P}\left(20,0 \mathrm{mg} \mathrm{dm}^{-3}\right)$, M.O. (37 $\left.\mathrm{g} \mathrm{kg}^{-1}\right), \mathrm{pH}\left(\mathrm{CaCl}_{2}\right)(5,8), \mathrm{K}\left(0,5 \mathrm{mmol}_{\mathrm{c}} \mathrm{dm}^{-3}\right), \mathrm{Ca}$ $\left(29,5 \mathrm{mmol}_{\mathrm{c}} \mathrm{dm}^{-3}\right), \mathrm{Mg}\left(7,0 \mathrm{mmol}_{\mathrm{c}} \mathrm{dm}^{-3}\right), \mathrm{H}+\mathrm{Al}(42,7$ $\left.\mathrm{mmol}_{\mathrm{c}} \mathrm{dm}^{-3}\right)$, CTC $\left(79,7 \mathrm{mmol}_{\mathrm{c}} \mathrm{dm}^{-3}\right)$ e V $(46 \%)$.

$\mathrm{O}$ experimento foi instalado no mês de dezembro de 2006. A semeadura ocorreu em 19/12/2006. Utilizou-se semeadora (vácuo) ajustada para 10 sementes por metro, em espaçamento de $0,9 \mathrm{~m}$ entre linhas, a fim de obter um estande final de 100 mil plantas por hectare. 
A adubação de semeadura foi de $450 \mathrm{~kg} \mathrm{ha}^{-1}$ da fórmula $\mathrm{N}-\mathrm{P}_{2} \mathrm{O}_{5}-\mathrm{K}_{2} \mathrm{O}, \quad 5-22-10+$ micronutrientes (Fosmag 626.2 M4). A adubação de cobertura foi de $200 \mathrm{~kg} \mathrm{ha}^{-1}$ de ureia e $90 \mathrm{~kg} \mathrm{ha}^{-1}$ de $\mathrm{KCl}$ aplicados após os 25 dias da emergência da cultura. O controle de plantas daninhas, quando necessário, foi realizado através de manejo químico.

Aos 15 e 30 dias após a emergência foi realizada a aplicação dos herbicidas pirithiobaque-sodico (Staple) + trifloxissulfuron-sodico (Envoke) + fluazifope-pbutilico (Fusilade EW), na dose de $42 \mathrm{~g}$ i.a. $\mathrm{ha}^{-1}+2 \mathrm{~g}$ i.a $\mathrm{ha}^{-1}+75 \mathrm{~g}$ i.a. ha ${ }^{-1}$. Aos 50 dias após a emergência foi realizada a aplicação dos herbicidas Diuron (Diurex 500) + MSMA (Volcane) nas doses de $1000 \mathrm{~g} \mathrm{i.a} \mathrm{ha}^{-1}+$ $1440 \mathrm{~g}$ i.a. ha ${ }^{-1}$ em jato dirigido, na entre linha da cultura. Utilizou-se o regulador de crescimento cloreto de mepiquate (Pix HC) na dose de 15 g i.a ha ${ }^{-1}$ conforme a exigência da cultura.

O controle de doenças foi realizado com os fungicidas flutriafol + tiofanato metílico (Impact Duo) na dose de $60+300$ g i.a. ha ${ }^{-1}$; flutriafol + tiofanato metílico (Impact Duo) + hidróxido de fentina (Mertin) nas doses de $(60+300)+120$ g i.a. ha ${ }^{-1}$ e tebuconazol + trifloxistrobina (Nativo) na dose de $50+100 \mathrm{~g}$ i.a. ha ${ }^{-1}$, aos 50, 70 e 90 dias após a emergência da cultura, respectivamente.

Todas as pulverizações foram realizadas utilizandose pulverizador tratorizado, com volume de calda estabelecido em $150 \mathrm{~L} \mathrm{ha}^{-1}$. As temperaturas durante as aplicações variaram de 25 a $30{ }^{\circ} \mathrm{C}$ e umidade relativa variou de 50 a $70 \%$. O delineamento foi em blocos casualisados, em esquema fatorial $2 \times 3$, num total de seis tratamentos, com cinco repetições, totalizando 30 parcelas. Cada parcela foi constituída por 14 metros de largura e $30 \mathrm{~m}$ de comprimento, com dois metros de cada lado da parcela, atuando como bordadura, considerando-se como área útil $420 \mathrm{~m}^{2}$.

Os tratamentos foram: 1) Cultivar Nuopal (com inseticida) $(100 \% \mathrm{Bt})$; 2) Cultivar Deltaopal (com inseticida) (100\% não Bt); 3) Cultivar Nuopal centro (80\%) e bordadura Deltaopal $(20 \%)$ (com inseticida) $(80 \%$ Bt $+20 \%$ não Bt); 4) Cultivar Nuopal (sem inseticida) $(100 \% \mathrm{Bt})$; 5) Cultivar Deltaopal (sem inseticida) (100\% não Bt) e 6) Cultivar Nuopal centro $(80 \%)$ e bordadura Deltaopal (sem inseticida) $(80 \% \mathrm{Bt}+$ $20 \%$ não Bt).

As pulverizações para controle de lagartas foram realizadas com os inseticidas metomil (Lannate) na dose de $172 \mathrm{~g}^{\mathrm{i}} \mathrm{a} \mathrm{ha}{ }^{-1}$, lufenuron (Match) na dose de $15 \mathrm{~g}$ i.a $\mathrm{ha}^{-1}$ e spinosad (Tracer) na dose de $48 \mathrm{~g}$ i.a ha ${ }^{-1}$. A tomada de decisão para o controle foi realizada de acordo com os níveis de controle descritos por Papa (2006): $40 \%$ de plantas infestadas (A. argillacea) e 10\% de plantas infestadas (H. virescens e $S$. frugiperda).
Foram realizadas amostragens no período de 37 aos 134 dias após a emergência (DAE) da cultura, contando-se o número de lagartas (A. argillacea, $H$. virescens e $S$. frugiperda) em dez plantas por parcela. Os dados foram submetidos à análise de variância pelo teste $\mathrm{F}$ e as médias comparadas pelo teste de Tukey $(5 \%)$.

\section{Resultados e Discussão}

Ocorreram diferenças significativas isoladas (cultivares-C e manejo-M) em algumas datas avaliadas e ocorreram interações significativas $\left(\begin{array}{lll}C & \mathrm{x} & \mathrm{M}\end{array}\right)$, no número médio de lagartas de A. argillacea na safra 2006/07 (Tabela 1). Observou-se a ocorrência da praga no período de 37 aos 134 dias após a emergência (DAE).

Analisando as avaliações de forma geral, nenhuma das cultivares se destacou no controle da lagarta. Apesar de não expressar significativamente menor número na comparação entre tratamentos em todas as avaliações, observa-se que o tratamento $100 \%$ Bt-Nuopal apresentou menor quantidade de lagartas em seis das oito avaliações realizadas, provavelmente por ação da toxina de $B$. thuringiensis que forma cristais no intestino das lagartas, causando um desequilíbrio osmótico e iônico, levando a morte do inseto por inanição (BRAVO et al., 2007). A utilização de $100 \%$ do algodão Bt apresenta aspecto negativo, principalmente devido à alta probabilidade de desenvolvimento de lagartas resistentes as toxinas Cry (PERLAK et al., 2001).

Quanto ao efeito de inseticida observa-se que o uso de inseticida diferiu significativamente do tratamento sem inseticida, apresentando melhor controle na maioria das avaliações, somente nas avaliações aos 37 e 110 DAE que não houve diferenças. Houve interação entre manejo de cultivares e uso de inseticidas aos 45, 69 e 88 DAE (Tabela 2).

De modo geral, o tratamento $100 \%$ não $B t$-Deltaopal sem inseticida apresentou a maior quantidade de lagartas, indicando a necessidade do uso de inseticida no caso de cultivares não resistente. Nota-se também que a cultivar $100 \%$ Bt-Nuopal apresentou maior quantidade de lagarta na primeira avaliação (45 DAE) (Tabela 2), porém, nas outras duas avaliações houve redução desse número. Pode-se deduzir que houve uma redução populacional no decorrer das avaliações por ação da toxina. A produção da toxina varia ao longo do desenvolvimento fenológico e nas diferentes partes da planta de algodão. Essa variabilidade pode resultar em diferenças na susceptibilidade das lagartas em diferentes períodos de exposição às toxinas Cry (TORRES et al., 2006). 
Tabela 1. Número médio de A. argillacea por tratamento aos 37, 45, 52, 69, 88, 95, 110 e 134 dias após a emergência (DAE) e valores do teste F. Chapadão do Sul, MS.

\begin{tabular}{lcccccccc}
\hline \multirow{2}{*}{ Tratamentos } & \multicolumn{7}{c}{ Dias após a emergência (DAE) } \\
\cline { 2 - 8 } & 37 & 45 & 52 & 69 & 88 & 95 & 110 & 134 \\
\hline $100 \%$ Bt-Nuopal & $0,10 \mathrm{a}$ & $1,30 \mathrm{ab}$ & $0,60 \mathrm{~b}$ & $0,90 \mathrm{~b}$ & $1,80 \mathrm{~b}$ & $1,70 \mathrm{a}$ & $0,30 \mathrm{a}$ & $0,90 \mathrm{a}$ \\
$100 \%$ não Bt-Deltaopal & $0,50 \mathrm{a}$ & $2,30 \mathrm{a}$ & $1,50 \mathrm{a}$ & $1,90 \mathrm{~b}$ & $14,30 \mathrm{a}$ & $4,30 \mathrm{a}$ & $1,70 \mathrm{ab}$ & $1,50 \mathrm{a}$ \\
$80 \% \mathrm{Bt}+20 \%$ não Bt & $0,80 \mathrm{a}$ & $0,60 \mathrm{~b}$ & $0,80 \mathrm{ab}$ & $4,60 \mathrm{a}$ & $1,80 \mathrm{~b}$ & $12,50 \mathrm{~b}$ & $2,90 \mathrm{~b}$ & $1,70 \mathrm{a}$ \\
\hline Com inseticidas & $0,33 \mathrm{a}$ & $0,60 \mathrm{~b}$ & $0,60 \mathrm{~b}$ & $1,80 \mathrm{~b}$ & $4,33 \mathrm{~b}$ & $3,87 \mathrm{~b}$ & $1,60 \mathrm{a}$ & $0,73 \mathrm{~b}$ \\
Sem inseticidas & $0,60 \mathrm{a}$ & $2,20 \mathrm{a}$ & $1,33 \mathrm{a}$ & $3,13 \mathrm{a}$ & $7,60 \mathrm{a}$ & $8,47 \mathrm{a}$ & $1,66 \mathrm{a}$ & $2,00 \mathrm{a}$ \\
\hline Teste F & & & & & & & \\
F (Cultivares) & $2,86^{\mathrm{NS}}$ & $5,46^{*}$ & $4,77^{*}$ & $34,08^{* *}$ & $82,63^{* *}$ & $11,37^{*}$ & $8,40^{*}$ & $1,16^{\mathrm{NS}}$ \\
F (Manejo de inseticidas) & $0,99^{\mathrm{NS}}$ & $18,30^{*}$ & $9,18^{*}$ & $10,31^{*}$ & $4,74^{*}$ & $4,61^{*}$ & $0,31^{\mathrm{NS}}$ & $9,25^{*}$ \\
F (CxM) & $1,27^{\mathrm{NS}}$ & $17,73^{*}$ & $2,54^{\mathrm{NS}}$ & $5,97^{*}$ & $9,87^{*}$ & $0,34^{\mathrm{NS}}$ & $0,08^{\mathrm{NS}}$ & $1,62^{\mathrm{NS}}$ \\
\hline C.V. $(\%)$ & 20,55 & 20,09 & 17,70 & 14,90 & 18,81 & 39,16 & 28,67 & 25,65 \\
\hline
\end{tabular}

Médias seguidas da mesma letra minúscula na coluna, não diferem significativamente pelo teste Tukey a 5\% de probabilidade. NS= não significativo. $*=$ significativo a $5 \%$ de probabilidade. $* *=$ significativo a $1 \%$ de probabilidade.

Tabela 2. Interação entre cultivares e Manejo de inseticidas (Com e Sem) sobre A. argillacea em algodoeiro. Número médio de lagartas por tratamento aos 45, 69 e 88 dias após a emergência (DAE). Chapadão do Sul, MS.

\begin{tabular}{llllllll}
\hline \multicolumn{1}{c}{ Cultivares } & Com & Sem & Com & Sem & Com & Sem \\
\cline { 2 - 8 } & & 45 & & & 69 & & 88 \\
\hline $100 \%$ Bt-Nuopal & $0 \mathrm{Ba}$ & $5 \mathrm{Aa}$ & $2 \mathrm{Aab}$ & $2 \mathrm{Ab}$ & $2 \mathrm{Ab}$ & $\mathrm{Ab}$ \\
$100 \%$ não Bt-Deltaopal & $1 \mathrm{Aa}$ & $2 \mathrm{Ab}$ & $3 \mathrm{Ba}$ & $6 \mathrm{Aa}$ & $9 \mathrm{Ba}$ & $20 \mathrm{Aa}$ \\
$80 \% \mathrm{Bt}+20 \%$ não Bt & $1 \mathrm{Aa}$ & $0 \mathrm{Ab}$ & $1 \mathrm{Ab}$ & $1 \mathrm{Ab}$ & $2 \mathrm{Ab}$ & $2 \mathrm{Ab}$ \\
\hline
\end{tabular}

Médias seguidas da mesma letra maiúscula na linha e minúscula na coluna, não diferem significativamente pelo teste Tukey a 5\% de probabilidade.

Não houve diferença significativa entre as cultivares, indicando que a toxina de $B$. thuringiensis não teve efeito sobre $S$. frugiperda no presente trabalho. Os resultados aqui obtidos são semelhantes ao observado por Rie et al. (1990) que verificaram a tolerância de algumas espécies de Spodoptera às proteínas Cry1Aa e Cry1 Ab, presentes em algodoeiro transgênico. Diante de tais resultados pode se inferir que $S$. frugiperda também é tolerante à proteína Cry1 Ac, pois segundo CTNBio (2005) a cultivar de algodão transgênico Nuopal expressa a referida toxina. Sebastião et al. (2015) citam que os insetos tolerantes à proteínas de $B$. thuringiensis, como as lagartas de $S$. cosmioides, $S$. eridania e $S$. frugiperda, tolerantes à proteína Cry1Ac, conseguem sobreviver mesmo submetidos a elevados níveis de concentração.

Assim como mencionado por Almeida et al. (2008), as lagartas de A. argillacea são importantes pragas pois infestam as plantas logo no início do desenvolvimento da cultura causando destruição da área foliar e queda acentuada na produção. Ainda conforme apresentado pela CTNBio (2005), o algodão geneticamente modificado $(B t)$ tem proporcionado aos agricultores um efetivo avanço no combate aos lepidópteros-praga em vários países, pois a maior ocorrência de A. argillacea foi ao algodoeiro $100 \%$ não $B t$ sem inseticida, principalmente no mês de março, atingindo o maior valor populacional no decorrer do experimento, enquanto neste mesmo mês o algodão Bt sem inseticida apresentava números menores. Lagartas de $H$. virescens ocorreram no período de 81 aos 117 DAE (Tabela 3).

Analisando o efeito das cultivares, $100 \%$ não BtDeltaopal obteve menor controle de $H$. virescens, diferindo significativamente dos demais tratamentos em todas as amostragens. Só não diferindo apenas do tratamento $80 \% \mathrm{Bt}+20 \%$ não $\mathrm{Bt}$ aos $117 \mathrm{DAE}$, porém, nas demais amostragens houve diferença. Este resultado demonstra o efetivo controle da toxina de $B$. thuringiensis à referida lagarta (Tabela 3). Quanto ao manejo de inseticidas, o melhor controle foi obtido com uso de inseticida, diferindo significativamente do tratamento sem inseticida em três das quatro amostragens.

Houve interação entre cultivares e manejo de inseticida nas avaliações aos 81, 103 e 110 DAE (Tabela 4). Lagartas de $S$. frugiperda ocorreram no período de 69 aos 117 DAE (Tabela 5). Analisando as três avaliações que ocorreram interação entre cultivares $x$ manejo de inseticida, observa-se que o uso de cultivares resistentes pela ação da toxina de $B$. thuringiensis tem efetivo controle contra $H$. virescens sem a necessidade do uso de inseticida, tornando esta tecnologia uma importante ferramenta no manejo fitossanitário. Porém, o uso de inseticida é necessário no manejo de cultivares não resistentes, podendo observar que houve maior número de lagartas no tratamento sem inseticida no cultivar $100 \%$ não Bt-Deltaopal, comparado ao tratamento com inseticida. 
Tabela 3. Número médio de $H$. virescens por tratamento aos 81, 103, 110 e 117 dias após a emergência (DAE) e valores do teste F. Chapadão do Sul, MS.

\begin{tabular}{lcccc}
\hline \multicolumn{1}{c}{ Tratamentos } & 81 & 103 & 110 & 117 \\
\hline $100 \%$ Bt-Nuopal & $0,00 \mathrm{~b}$ & $0,60 \mathrm{~b}$ & $0,40 \mathrm{~b}$ & $0,80 \mathrm{~b}$ \\
$100 \%$ não Bt-Deltaopal & $0,90 \mathrm{a}$ & $6,20 \mathrm{a}$ & $3,30 \mathrm{a}$ & $5,20 \mathrm{a}$ \\
$80 \% \mathrm{Bt}+20 \%$ não Bt & $0,00 \mathrm{~b}$ & $0,40 \mathrm{~b}$ & $0,50 \mathrm{~b}$ & $2,00 \mathrm{ab}$ \\
\hline Com inseticidas & $0,06 \mathrm{~b}$ & $2,00 \mathrm{~b}$ & $1,00 \mathrm{~b}$ & $2,26 \mathrm{a}$ \\
Sem inseticidas & $0,53 \mathrm{a}$ & $2,80 \mathrm{a}$ & $1,80 \mathrm{a}$ & $3,06 \mathrm{a}$ \\
\hline Teste F & & & $30,58^{* *}$ & $4,13^{*}$ \\
F (Cultivares) & $13,27^{*}$ & $135,22^{* *}$ & $3,28^{*}$ & $0,23^{\mathrm{NS}}$ \\
F (Manejo de inseticidas) & $7,43^{*}$ & $4,80^{*}$ & $4,99^{*}$ & $2,08^{\mathrm{NS}}$ \\
F (CxM) & $7,43^{*}$ & $1,98^{*}$ & 18,83 & 48,13
\end{tabular}

Médias seguidas da mesma letra minúscula na coluna, não diferem significativamente pelo teste Tukey a 5\% de probabilidade. NS= não significativo. $*=$ significativo a $5 \%$ de probabilidade. $* *=$ significativo a $1 \%$ de probabilidade.

Tabela 4. Interação entre cultivares e manejo de inseticidas (com e sem) sobre $H$. virescens em algodoeiro. Número médio de lagartas por tratamento aos 81, 103 e 110 dias após a emergência (DAE). Chapadão do Sul, MS.

\begin{tabular}{|c|c|c|c|c|c|c|}
\hline \multirow[t]{2}{*}{ Cultivares } & Com & Sem & Com & Sem & Com & Sem \\
\hline & \multicolumn{2}{|c|}{81} & \multicolumn{2}{|c|}{103} & \multicolumn{2}{|c|}{110} \\
\hline 100\% Bt-Nuopal & $0 \mathrm{Aa}$ & $\mathrm{OAb}$ & $\mathrm{OBb}$ & $1 \mathrm{Ab}$ & $0 \mathrm{Aa}$ & $0 \mathrm{Ab}$ \\
\hline $100 \%$ não Bt-Deltaopal & $0 \mathrm{Ba}$ & $2 \mathrm{Aa}$ & $5 \mathrm{Aa}$ & $7 \mathrm{Aa}$ & $2 \mathrm{Bb}$ & $5 \mathrm{Aa}$ \\
\hline $80 \% \mathrm{Bt}+20 \%$ não $\mathrm{Bt}$ & $0 \mathrm{Aa}$ & $0 \mathrm{Ab}$ & $0 \mathrm{Ab}$ & $0 \mathrm{Ab}$ & $0 \mathrm{Aa}$ & $0 \mathrm{Ab}$ \\
\hline
\end{tabular}

Médias seguidas da mesma letra maiúscula na linha e minúscula na coluna, não diferem significativamente pelo teste Tukey a 5\% de probabilidade.

Tabela 5. Número médio de $S$. frugiperda por tratamento aos 69, 81, 88 e 117 dias após a emergência (DAE) e valores do teste F. Chapadão do Sul, MS.

\begin{tabular}{lcccc}
\hline \multicolumn{1}{c}{ Tratamentos } & \multicolumn{4}{c}{ Dias após a emergência (DAE) } \\
\cline { 2 - 5 } & 69 & 81 & 88 & 117 \\
\hline $100 \%$ Bt-Nuopal & $3,50 \mathrm{a}$ & $2,20 \mathrm{a}$ & $1,90 \mathrm{a}$ & $0,50 \mathrm{a}$ \\
$100 \%$ não Bt-Deltaopal & $4,20 \mathrm{a}$ & $2,50 \mathrm{a}$ & $2,40 \mathrm{a}$ & $1,30 \mathrm{a}$ \\
$80 \%$ Bt + 20\% não Bt & $4,50 \mathrm{a}$ & $2,90 \mathrm{a}$ & $4,30 \mathrm{a}$ & $3,60 \mathrm{a}$ \\
\hline Com inseticidas & $2,47 \mathrm{~b}$ & $1,53 \mathrm{~b}$ & $0,73 \mathrm{~b}$ & $1,53 \mathrm{a}$ \\
Sem inseticidas & $5,67 \mathrm{a}$ & $3,53 \mathrm{a}$ & $5,00 \mathrm{a}$ & $2,07 \mathrm{a}$ \\
\hline Teste F & & & & $2,91^{\mathrm{NS}}$ \\
F (Cultivares) & $1,61^{\mathrm{NS}}$ & $0,90^{\mathrm{NS}}$ & $2,99^{\mathrm{NS}}$ & $0,01^{\mathrm{NS}}$ \\
F (Manejo de inseticidas) & $38,09^{*}$ & $19,43^{*}$ & $32,71^{*}$ & $3,04^{\mathrm{NS}}$ \\
F (CxM) & $0,28^{\mathrm{NS}}$ & $0,72^{\mathrm{NS}}$ & $0,02^{\mathrm{NS}}$ & 30,43 \\
\hline C. V. (\%) & 14,22 & 17,88 & & 44,78 \\
\hline
\end{tabular}

Médias seguidas da mesma letra minúscula na coluna, não diferem significativamente pelo teste Tukey a 5\% de probabilidade. NS= não significativo. $*=$ significativo a $5 \%$ de probabilidade. $* *=$ significativo a $1 \%$ de probabilidade.

Já o uso de inseticida proporcionou melhores resultados em comparação ao tratamento sem inseticida, havendo diferenças significativas nas avaliações aos 69, 81 e 88 DAE (Tabela 5). Dessa forma, torna-se necessário enfatizar a importância do uso de inseticida no manejo fitossanitário, lembrando que este método ainda é o de maior eficiência no controle de insetospraga na cultura do algodão. Assim como foi observado no presente trabalho, o tratamento com inseticida diferiu significativamente do tratamento sem inseticida no controle das lagartas A. argillacea, $H$. virescens e $S$. frugiperda, apresentando maior controle. Não houve diferença estatística na interação entre as variáveis observadas para $S$. frugiperda.

\section{Conclusões}

A ocorrência de A. argillacea e $\mathrm{H}$. virescens foi menor nos tratamentos com a cultivar transgênica. Não ocorreram diferenças entre a cultivares quanto à ocorrência de S. frugiperda. O manejo das cultivares com inseticida obteve maior eficiência comparada ao tratamento sem inseticida no controle das lagartas.

\section{Referências Bibliográficas}

ALMEIDA, R. P.; SILVA, C. A. D.; RAMALHO, F. S. Manejo integrado de pragas do algodoeiro no Brasil. In: BELTRÃO, N. E. M.; AZEVEDO, D. M. P. (Eds.) O 
Agronegócio do algodão no Brasil. Brasília-DF: EMBRAPA, 2008, p.1033-1098.

BLANCO, C.; VARGAS, A. T.; LOPEZ, J.; KAUFMANN, J. Naturally-occurring densities of Heliothis virescens and Helicoverpa zea (lepidoptera: noctuidae) in three different plant hosts. Florida Entomologist, Florida-USA, v. 90, n. 4, p. $742-751,2007$.

BRAVO, A.; GILL, S. S.; SOBERON, M. Mode of action of Bacillus thuringiensis Cry and Cyt toxins and their potential for insect control. Toxicon, Cuernavaca-México, v. 49, n. 4, p. 423-435, 2007.

CONAB. Companhia Nacional de Abastecimento. Acompanhamento da safra brasileira: grãos. Safra 2014/2015 - décimo segundo levantamento. Brasília-DF. 2015. Disponível em: 〈www.conab.gov.br> Acesso em: 10 set. 2015 .

CTNBio. COMISSÃO TÉCNICA NACIONAL DE BIOSSEGURANÇA. Parecer $N^{0} \mathbf{0 5 1 3 / 2 0 0 5}$ - Liberação Comercial de Algodão Geneticamente Modificado Resistente a Insetos Evento 531. Processo 01200.001471/2003-01: Parecer Técnico Prévio Conclusivo. Brasília-DF. 2005. Disponível em: < http://ctnbio.mcti.gov.br/> Acesso em: 23 maio 2016.

EMBRAPA. EMPRESA BRASILEIRA DE PESQUISA AGROPECUÁRIA. Centro Nacional de Pesquisa do Solo. Sistema brasileiro de classificação de solos. Brasília-DF: Embrapa SPI; Embrapa Solos, 2006. 306p.

FERNANDES, M. G.; SILVA, A. M.; DEGRANDE, P. E.; CUBAS, A. C. Distribuição vertical de lagartas de Alabama argillacea (Hübner) (Lepidoptera: Noctuidae) em plantas de algodão. Manejo Integrado de Plagas y Agroecologia, Turrialba-Costa Rica, v. 1, n. 78, p. 28-35, 2006.

FONTES, E. M. G.; RAMALHO, F. S.; UNDERWOOD, E.; BARROS, P. A. V.; SIMON, M. F.; SUJII, E. R.; PIRES, C. S. S.; BELTRÃO, N.; LUCENA,W. A.; FREIRE, E. C. The cotton agricultural context in Brazil. In: HILBECK, A.; ANDOW, D. A.; FONTES, E. M. G. (Ed.). Environmental risk assessment of genetically modified organisms: methodologies for assessing Bt cotton in Brazil. Wallingford: CABI, 2006. p.21 66.

JAMES, C. Global status of commercialized biotech/GM crops: 2009. Ithaca-NY: ISAAA Briefs 39, 2009.

PAPA, G. Pragas e seu controle. In: MORESCO, E. (Org.). Algodão: pesquisas e resultados para o campo. Cuiabá-MT: FACUAL, 2006, p. 206-239.
PERLAK, F. J.; OPPENHUIZEN, M.; GUSTAFSON, K.; VOTH, R.; SIVASUPRAMANIAM, S.; HEERING, D.; CAREY, B.; IHRIG, R. A.; ROBERTS, J. K. Development and commercial use of Bollgard ${ }^{\circledR}$ cotton on the USA - early promises versus today's reality. Plant Journal, Oxford-UK, v. 1, n. 27, p. 489-501, 2001.

PINTO, L. M. N.; FIUZA, L. M. Genes cry de Bacillus thuringiensis aplicados na engenharia genética de plantas, conferindo resistência a insetos-praga. Neotropical Biology and Conservation, São Leopoldo-RS, v. 3, n. 3, p. 159-168, 2008.

RIE, J. VAN; McGAUGHEY, W. H.; JOHNSON, D. E.; BARNETT, B. D.; MELLAERT, H. VAN. Mechanism of insect resistance to the microbial insecticide Bacillus thuringiensis. Science, Danvers-USA, v. 247, n. 29, p. 72-74, 1990.

SANTOS, R. L.; TORRES, J. B. Produção da proteína Cry1Ac em algodão transgênico e controle de lagartas. Revista Brasileira de Ciências Agrarias, Recife-PE, v. 5, n. 4, p. 509-517, 2010

SEBASTIÃO, I.; LEMES, A. R. N.; FIGUEIREDO, C. S.; POLANCZYK, R. A.; DESIDÉRIO, J. A.; LEMOS, M. V. F. Toxicidade e capacidade de ligação de proteínas Cry1 a receptores intestinais de Helicoverpa armigera (Lepidoptera: Noctuidae). Pesquisa Agropecuária Brasileira, Brasília-DF, v. 50, n. 11, p. 999-1005, 2015.

TOMQUELSKI, G. V.; MARTINS, G. L. M. Pragas em algodoeiro na região dos Chapadões. Safra 2012/2013. Pesquisa, Tecnologia e Produtividade, Chapadão do SulMS, v. 1, n. 1, p. 25-51, 2013.

TOMQUELSKI, G.V.; MARTINS, G. L. M.; PAPA, G. Efeito dos indutores de resistência acibenzolar-s-metil e silício na biologia de Alabama argillacea (Lepidotera: Noctuidae) em algodoeiro. Revista de Agricultura, Piracicaba-SP, v. 82, n. 2, p. 170-175, 2007.

TORRES, J. B. Controle de pragas do algodoeiro: expectativas de mudanças. Ciência Agrícola, Maceió-AL, v. 8, n. 1, p. $37-$ $49,2008$.

TORRES, J.B.; RUBERSON, J.R.; ADANG, M.J. Expression of Bacillus thuringiensis Cry1Ac protein in cotton plants, acquisition by pests and predators: a tritrophic analysis. Agricultural and Forest Entomology, St Albans, v.8, n.3, p.191-202, 2006.

TORRES，J.B.; RUBERSON，J.R.; WHITEHOUSE，M. Transgenic cotton for sustainable pest management: a review. In: LICHTFOUSE, E. (Ed.). Organic farming, pest control and remediation of soil pollutants: sustainable agriculture reviews. Dordrecht-Holland: Springer, 2009. p.15-54. 